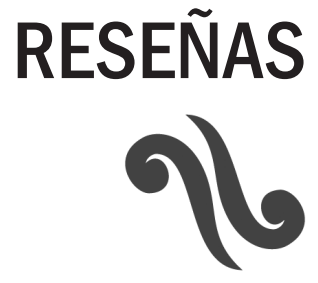





\title{
El reconocimiento social en el pensamiento europeo*
}

\author{
Roberto García Jurado
}

Axel Honneth es uno de los filósofos contemporáneos con más prestigio, basado en una amplia y sólida producción académica. Heredero directo de la Escuela de Frankfurt, de cuya tercera generación es una de las figuras más destacadas, es además discípulo distinguido de Jürgen Habermas. Honneth se ha labrado este gran prestigio por desarrollar y exponer su teoría del reconocimiento, la cual ha venido construyendo en una serie de trabajos que forman ya una larga lista, de entre los cuales podemos mencionar La lucha por el reconocimiento (1997), Critica del agravio moral (2009); La sociedad del desprecio (2011), y el Derecho a la libertad (2014), entre muchos otros.

En Reconocimiento. Una historia de las ideas en Europa (2019) emprende un análisis de la evolución de las nociones y conceptos relacionados con la teoría del reconocimiento que se han producido en tres países, Francia, Gran Bretańa y Alemania, los tres países con las más sólidas tradiciones culturales e intelectuales en lo que respecta a este campo de reflexión.

La reflexión que emprende Honneth se basa en la concepción de que las ideas y conceptos del pensamiento filosófico, sociológico y político que se desarrollan en un país están íntimamente relacionadas con su época y circunstancia. Esto significa que más allá de la evolución interna de una disciplina, o del contacto de ésta con los desarrollos que se dan en su mismo campo en otros países, hay una relación muy estrecha entre su contenido y los acontecimientos sociales que la circundan. No obstante, aunque Honneth hace esta observación desde el primer capítulo, en el cuerpo del trabajo no realiza más que contadas reflexiones en este sentido, con lo cual deja una cierta expectación en el lector de un mayor abundamiento en esta relación y conexión.

* Reseña de la obra de Axel Honneth, Reconocimiento. Una historia de las ideas en Europa, Madrid, Akal, 2019 (versión Kindle). 


\section{R. GARCíA JURADO EL RECONOCIMIENTO SOCIAL EN EL PENSAMIENTO EUROPEO}

En el núcleo de su teoría del reconocimiento, Honneth sitúa la afirmación de que las relaciones entre los sujetos se caracterizan por una dependencia reciproca del aprecio o reconocimiento de los demás, es decir, que las relaciones entre los diferentes individuos que conforman una sociedad no se basan o circunscriben únicamente a las relaciones puramente materiales o físicas, sino que la dependencia mutua rebasa el contorno de este universo material y asciende hasta una esfera psicológica y moral, en donde la posición y valoración de cada individuo depende directamente de la imagen de sí mismo que vea reflejada en los demás, del reconocimiento que logre con ello.

Así, la necesidad y exigencia de reconocimiento se percibe claramente en tres campos sociales y políticos: primero, en la demanda de igualdad de derechos entre los miembros de una comunidad cooperativa, como lo es la sociedad; segundo, en el apremio por el reconocimiento incondicional del otro, de los otros; y tercero, en la aceptación e incorporación de las minorías culturales que ahora ya están presentes en casi todas las sociedades del mundo.

De los tres casos nacionales que Honneth analiza, comienza por el de Francia, en donde ubica el origen de la moderna teoría del reconocimiento. De acuerdo con Honneth, el fundador de ésta es nada menos que el ginebrino Jean Jacques Rousseau. Es en su Discurso sobre el origen y fundamentos de la desigualdad donde sienta las bases de sus ideas sobre el reconocimiento, afirmando que la búsqueda y necesidad de reconocimiento social es fruto de un largo proceso histórico, el cual propició que en su época la exigencia de aparentar mayor valía y rango que los demás fuera imperativa. Así, el amour propre que se anida al interior de los individuos los impulsa y condiciona para guiar sus actos de acuerdo con el juicio de los demás, haciendo depender su propia conducta de la opinión de los otros que se encuentran alrededor.

Sin embargo, lejos de valorar positivamente esta relación, Rousseau la reprueba de manera absoluta, pues considera que cuando un individuo norma su conducta condicionado por la opinión de los demás, tiende a fingir talentos y capacidades que no tiene, tiende a no ser franco ni auténtico.

Por la misma época de Rousseau, el gran moralista La Rochefoucauld exponía una teoría muy similar en sus Máximas. Ahí, planteaba que en cuanto más valorado quiera ser un individuo por los otros, más fingirá en público tener talentos y virtudes de los que carece, lo que no sólo constituirá una mentira social, sino que además podría desembocar en que el individuo acabe por engañarse a sí mismo.

En su recuento, Honneth no se detiene a analizar otros autores de la Ilustración ni a autores del siglo XIX tan relevantes como Comte. Ciertamente hace algunos comentarios sobre Durkheim, pero se puede decir que su análisis salta desde Rousseau hasta Sartre en el siglo XX. Plantea entonces que para este último la búsqueda de reconocimiento social también es algo negativo, dado 
que en su persecución el sujeto dejaba su ser para sí y con ello perdía su libertad, su autonomía y autocontrol. De este modo, basado en este repaso histórico del pensamiento francés, Honneth concluye que en este país la lucha por el reconocimiento social se contempla de una manera muy negativa.

El caso de Gran Bretaña es diametralmente distinto al de Francia. Honneth pasa revista rápidamente a planteamientos relativos al reconocimiento expresados por Hobbes, Shaftesbury y Hutcheson, pero a quienes presta mayor atención es a David Hume y Adam Smith, particularmente al primero.

Honneth describe que en la Investigación sobre los principios de la moral y en el Tratado sobre la naturaleza humana Hume plantea que para relacionarse con los demás no basta con guiarse por el juicio del individuo aislado, sino que es necesario observar y considerar el juicio de ellos, realizar una operación mental para convertir ese juicio en una especie de observador interior de la propia conducta.

Esto significa que para la formación del juicio individual es necesario e imprescindible contar con un observador imparcial, función que no pueden desempeñar más que los individuos externos al sujeto. De este modo, si el individuo quiere obtener la aceptación y reconocimiento de los demás, su sympathy, debe tomar en cuenta sus opiniones e ideas, hacerlas parte de sus consideraciones a la hora de formarse un juicio. De este modo, la sympathy le permite al individuo no sólo tomar en cuenta la opinión y criterio de los demás, sino ponerse en el lugar de los otros, adoptar su perspectiva, para tratar de llegar a un juicio lo más adecuado y objetivo posible.

Honneth ubica en esta misma perspectiva de pensamiento a Adam Smith, a quien considera no solamente como un defensor incondicional de las ventajas del egoísmo económico. Señala que para Smith hay un impulso para contrastar las reacciones emocionales propias con las de los otros; con lo que podría considerarse un observador general, del cual se espera obtener aceptación y prestigio social.

Como puede observarse, en contraste con la tradición francesa, que asigna una valoración negativa a la lucha por el reconocimiento social, en la tradición británica hay una tendencia a una valoración positiva, tanto para obtener aceptación, prestigio y reconocimiento social, como para lograr una construcción más objetiva e imparcial de las propias opiniones de los individuos, esto es, un reconocimiento con efectos en el terreno moral y cognitivo.

En el caso de Alemania, Honneth centra su atención en tres pilares de su filosofía, Kant, Fichte y Hegel, cuya repercusión y renombre en el pensamiento moderno, sobre todo del primero y el tercero, son evidentes por sí mismos.

Así como la teoría del respeto se halla asociada con la expresión de amour propre en Francia y de sympathy en Gran Bretaña, en Alemania, de la mano de 


\section{R. GARCíA JURADO EL RECONOCIMIENTO SOCIAL EN EL PENSAMIENTO EUROPEO}

Kant, se asoció a la expresión de respeto, a partir de la cual evolucionó para dar paso al concepto de reconocimiento.

Para Kant, la necesidad de ese observador imparcial que enjuicie las opiniones propias debe ubicarse en la razón misma del sujeto, es decir, un individuo sólo está en condiciones de atender a los mandatos morales de la razón cuando éstos surgen de su interior mismo, de su foro interno. De este modo, el respeto que se confiere a los demás obedece a considerarlos seres morales plenos, como uno mismo, identificados así por la razón del sujeto.

Por su parte, Fichte criticaba a Kant diciendo que no debía considerarse el mundo objetivo sólo como un producto o efecto de la razón y actividad cognitiva del sujeto, sino como un efecto conjunto de su actividad general objetiva. Para Fichte, consecuentemente, en una relación intersubjetiva, uno no podía reconocer al otro si no se reconocían en su integridad, como seres libres que se debían el mismo trato recíproco.

Por su parte, Hegel consideraba que para una persona era muy importante ser reconocida tal cual por la otra, lo cual constituía un factor constitutivo de la misma idea de sí. En este sentido, Hegel planteaba que el reconocimiento mutuo entre los individuos era fundamental porque constituía un reforzamiento público de su yo individual.

Honneth dedica un capítulo conclusivo a presentar un resumen de toda la argumentación desarrollada en el libro, exponiendo que mientras en el pensamiento francés el reconocimiento tenía una connotación negativa, en el británico y alemán era positiva; mientras que en el pensamiento francés se advertía del peligro de la pérdida de sí por la búsqueda de status y prestigio social; en el británico se asumía el reconocimiento social como condición del autocontrol moral; y, finalmente, en el caso alemán, el reconocimiento mutuo permitía la autodeterminación personal. 


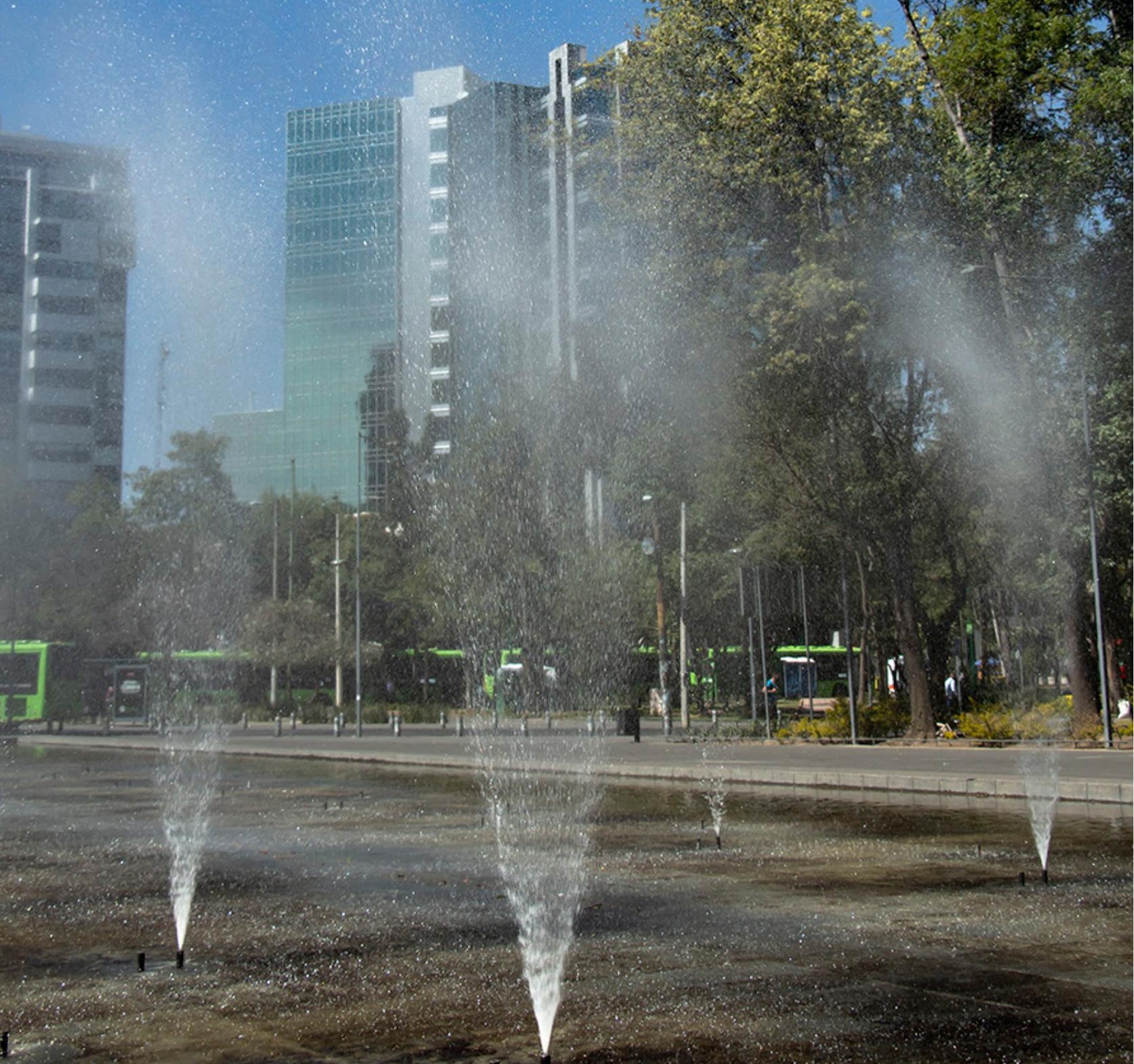


Fotografía | Iraís Hernández Güereca 